\title{
Essential Role for Synaptopodin in Dendritic Spine Plasticity of the Developing Hippocampus
}

\author{
Xiao-lei Zhang, ${ }^{1 \star}$ Beatrice Pöschel, ${ }^{1,3 \star}$ Christian Faul, ${ }^{4}$ Chirag Upreti, ${ }^{1,2}$ Patric K. Stanton, ${ }^{1,2}$ and Peter Mundel ${ }^{5}$ \\ ${ }^{1}$ Department of Cell Biology and Anatomy and ${ }^{2}$ Department of Neurology, New York Medical College, Valhalla, New York 10595, ${ }^{3}$ Center of Molecular \\ Neurobiology, University Medical Center Hamburg-Eppendorf, 20251 Hamburg, Germany, ${ }^{4}$ Department of Medicine, University of Miami Miller School of \\ Medicine, Miami, Florida 33136, and ${ }^{5}$ Harvard Medical School and Department of Medicine, Massachusetts General Hospital, Boston, Massachusetts 02129
}

Dendritic spines are a major substrate of brain plasticity. Although many studies have focused on $\mathrm{Ca}^{2+} / \mathrm{calmodulin}^{2} \mathrm{dependent}$ protein kinase II (CaMKII)-mediated regulation of spine dynamics and synaptic function in adult brain, much less is know about protein kinase A (PKA)-dependent regulation of spine shape dynamics during postnatal brain development. Synaptopodin is a dendritic spine associated modulator of actin dynamics and a substrate of PKA. Here we show that NMDA and cAMP-induced dendritic spine expansion is impaired in hippocampal slices from 15- and 21-d-old synaptopodin-deficient mice. We further show that synaptopodin is required for full expression of PKA-dependent hippocampal long-term potentiation in 15- and 21-d-old, but not adult, mice. PKA-induced cAMP response element-binding phosphorylation is normal in the hippocampus of synaptopodin-deficient mice, suggesting that synaptopodin functions independently of cAMP response element-binding. Our results identify synaptopodin as a substrate of PKA in hippocampal neurons and point to an essential role for synaptopodin in activity-dependent regulation of dendritic spine dynamics and synaptic plasticity in postnatal brain development.

\section{Introduction}

Dendritic spines are sites of synaptic plasticity mediated by localized increases in $\left[\mathrm{Ca}^{2+}\right]$ and dynamic regulation of the actin cytoskeleton (Matsuzaki et al., 2004; Schubert and Dotti, 2007; Honkura et al., 2008; Kasai et al., 2010). Induction of long-term potentiation (LTP) in the mature hippocampus requires activation of $\mathrm{Ca}^{2+} /$ calmodulin-dependent kinase II (CaMKII; Malenka and Nicoll, 1999; Kandel, 2001; Lisman et al., 2002). LTP induction requires coincident presynaptic and postsynaptic activity that elicits sufficient elevation in $\left[\mathrm{Ca}^{2+}\right] \mathrm{i}$ in dendritic spines to activate a number of $\mathrm{Ca}^{2+}$-stimulated enzymes, including CaMKII, $\mathrm{Ca}^{2+}$-stimulated adenylate cyclases that activate cAMP-dependent PKA and others (Dell'Acqua et al., 2006).

Synaptopodin is a regulator of actin dynamics and cell motility: it promotes RhoA signaling and suppresses Cdc42 signaling (Asanuma et al., 2006; Yanagida-Asanuma et al., 2007; Wong et al., 2012). In the brain, synaptopodin is strongly expressed by spine-bearing telencephalic neurons, where it is associated with the postsynaptic density (Mundel et al., 1997) and is necessary for

Received June 24, 2012; revised May 17, 2013; accepted June 12, 2013.

Author contributions: P.K.S. and P.M. designed research; X.-I.Z., B.P., C.F., and C.U. performed research; X.-I.Z., B.P., C.F., C.U., P.K.S., and P.M. analyzed data; P.K.S. and P.M. wrote the paper.

This work was supported by US National Institutes of Health Grants DA18886, DK57683 (to P.M.), and NS044421

(to P.S.). We thank Anna Greka, Boston, MA, for helpful discussions.

The authors declare no competing financial interests.

X.I.Z. and B.P. contributed equally to this work.

Correspondence should be addressed to either of the following: Dr Peter Mundel, Division of Nephrology, Massachusetts General Hospital, 149 13th Street, Charlestown, MA 02129, E-mail: mundel.peter@mgh.harvard.edu; or Dr Patric K. Stanton, Department of Cell Biology and Anatomy, New York Medical College, Basic Sciences Building, Room 217, Valhalla, NY 10595, E-mail: patric_stanton@nymc.edu.

DOI:10.1523/JNEUROSCI.2983-12.2013

Copyright $\odot 2013$ the authors $\quad 0270-6474 / 13 / 3312510-09 \$ 15.00 / 0$ formation of the dendritic spine apparatus (Deller et al., 2003). Expression of synaptopodin in the brain is developmentally regulated, becoming detectable by Western blot analysis $\sim 15 \mathrm{~d}$ of age, and reaching maximum expression in adult mice (Mundel et al., 1997). This temporal pattern coincidences with the development of spines and expression of LTP (Harris and Stevens, 1989), raising the possibility that the role of synaptopodin in regulating synaptic plasticity might change during development. Adult synaptopodin knock-out $\left(\right.$ synpo ${ }^{-/-}$) mice show reduced hippocampal LTP (Deller et al., 2003), and decreased $\alpha$-actinin-2 protein abundance in the hippocampus (Asanuma et al., 2005). Synaptopodin protein abundance increases during expression of LTP (Yamazaki et al., 2001), thereby further suggesting that synaptopodin contributes to the regulation of dendritic spine dynamics and synaptic function.

NMDA-receptor (NMDA-R)-dependent LTP is associated with persistent actin-dependent shape alterations of dendritic spines (Fukazawa et al., 2003; Lang et al., 2004; Yang et al., 2008). Postsynaptic PKA inhibition leads to unstable spine expansion and spontaneous collapse of LTP-induced spine expansions (Yang et al., 2008), but downstream mediators of PKAdependent spine expansion and stabilization are largely unknown. Synaptopodin is a substrate of PKA and phosphorylation of synaptopodin by PKA promotes 14-3-3 binding, which protects synaptopodin from cleavage by cathepsin L (CatL) and increases steady-state synaptopodin protein levels (Faul et al., 2008).

Here we show that NMDA and cAMP can induce PKAdependent increases in dendritic spine volume, and that these actions are impaired in hippocampal neurons of 15- and 21-dold synpo $^{-1-}$ mice. Furthermore, PKA-dependent hippocampal 
LTP is impaired in 15- and 21-d-old synpo ${ }^{-1-}$ mice. These findings reveal an important role for synaptopodin in the volumetric regulation and stability of dendritic spine shape during morphological alterations elicited by LTP. Our results identify synaptopodin as an essential downstream effector of PKA-dependent postnatal spine expansion and synaptic function that are believed to play important roles in the storage of long-term memories.

\section{Materials and Methods}

Electrophysiology. Male and female 15 d-, 21 d-, 2 month-, and 6-monthold synpo $^{-1-}$ and wild-type littermate mice in pure 129 or mixed (129C57BL/6) backgrounds (Asanuma et al., 2005) were decapitated under deep isoflurane anesthesia. The brains were quickly removed and hemisected, and tissue blocks containing the hippocampus were prepared. The blocks were fixed to a stage with cyanoacrylate glue and covered with ice-cold oxygenated artificial CSF (ACSF; in mM: $126 \mathrm{NaCl}, 3 \mathrm{KCl}, 1.25$ $\mathrm{NaH}_{2} \mathrm{PO}_{4}, 1.3 \mathrm{MgCl}_{2}, 2.5 \mathrm{CaCl}_{2}, 26 \mathrm{NaHCO}_{3}$, and 10 glucose; $2-4^{\circ} \mathrm{C}$ ). Four-hundred-micrometer-thick transverse hippocampal slices were cut with a vibratome (DSK DTK-1000), placed in an interface holding chamber at $32 \pm 1^{\circ} \mathrm{C}$ and allowed to recover for at least $1 \mathrm{~h}$ before the start of an experiment. For recording, slices were transferred to a Haas-style interface chamber at $32^{\circ} \mathrm{C} \pm 1{ }^{\circ} \mathrm{C}$, perfused with ACSF $(4 \mathrm{ml} / \mathrm{min})$ saturated with $95 \% \mathrm{O}_{2}$ and $5 \% \mathrm{CO}_{2}$ (Stanton et al., 2003, 2005). Field EPSPs (fEPSPs) were measured in CA1 stratum radiatum and evoked by stimulation of Schaffer collateral/commissural axons in stratum radiatum using a bipolar platinum stimulating electrode (Frederick Haer). Baseline stimulation frequency was $0.033 \mathrm{~Hz}$, with baseline stimulus intensities chosen to evoke half-maximal fEPSPs in stratum radiatum of field CA1. Baseline recordings of at least 20 min preceded the application of theta burst stimulation (TBS; $10 \times 4$ pulses with $200 \mathrm{~ms}$ interburst intervals and $10 \mathrm{~ms}$ intervals within each pulse) to induce LTP (Stanton et al., 2005), or low-frequency stimulus (LFS; $2 \mathrm{~Hz}$ for $10 \mathrm{~min}, 1200$ stimuli) to induce long-term depression (LTD; Stanton et al., 2003). Evoked potentials were monitored for $60 \mathrm{~min}$ subsequent to induction of either LTP or LTD.

Dynamic imaging analysis of dendritic spine expansion. After loading a CA1 pyramidal neuron with Alexa Fluor $594(100 \mu \mathrm{M})$ for $15 \mathrm{~min}$, tertiary dendrites were imaged using a $60 \times / 1.1 \mathrm{nA}$ water-immersion objective plus $4 \times$ digital zoom, as described previously (Zhang et al., 2008). $\mathrm{XYZ}$ scanning mode in a range of $\pm 3 \mu \mathrm{m}$ from focused layer was used to avoid movement bias, with a $z$-step interval of $0.5 \mu \mathrm{m}$, and each image took $0.45 \mathrm{~s}$ to finish, for a single depth profile time of $7 \mathrm{~s}$. Great care was taken to avoid both saturation of fluorescence and any signs of phototoxicity to small dendritic spines from too much excitation light. Depth profiles were repeated at $5 \mathrm{~min}$ intervals to reduce possible dye photobleaching and phototoxicity. A Mai/Tai laser (Solid State Laser) tuned to $810 \mathrm{~nm}$ was used for excitation, and image acquisition controlled by Olympus FluoviewFV300 software (Olympus America). In the transfluorescence pathway, a $565 \mathrm{~nm}$ dichroic mirror was used to separate green and red fluorescence, and passed through HQ525/50 and HQ605/50 emission filters, respectively, to eliminate transmitted or reflected excitation light (Chroma Technology), and detected simultaneously by two photonmultiplier tubes. The figures show projected images from the entire Z-profile, and these projections were used to calculate intensity as an index of spine volume.

Two-photon imaging of presynaptic transmitter release. FM1-43 fluorescence of single release sites was evoked by two-photon excitation, and visualized using a Olympus BX61WI upright microscope with a $60 \times 1$ $0.90 \mathrm{~W}$ water-immersion ultraviolet objective and multispectral confocal laser scan unit. The light source was a Mai-Tai laser (Solid State Laser) tuned to $840 \mathrm{~nm}$ center wavelength. Epifluorescence was detected with photonmultiplier tubes of the confocal laser scan head with pinhole maximally opened and emission spectral window optimized for signal over background (560-660 nm). Although we have seen no signs of photodamage, we use the lowest intensity necessary for adequate signal-tonoise ratio. We do not, in general, use compounds for quenching or enhance washout of nonspecifically bound FM1-43, as we have found these agents do not improve fluorescence signal-to-noise ratio using two- photon excitation (Winterer et al., 2006). For FM1-43 offline analyses, rectangular regions of interest $\left(\mathrm{ROI} \sim 2-4 \mu \mathrm{m}^{2}\right.$ ) were defined around the center of bright, punctate FM1-43 fluorescence spots, and 12-16 boutons and 3-4 background fields measured in each slice. If lateral displacement of a bouton beyond the ROI occurred, that dataset was discarded. Only puncta ( $\sim 90 \%)$ that showed stimulus-dependent unloading were included in analyses. All fields imaged were within the first $100 \mu \mathrm{m}$ in the slice, typically between 25 and $60 \mu \mathrm{m}$ deep, and were 40-60 $\mu \mathrm{m}$ away from stimulating electrode poles. A fluorescence time course was generated by normalizing each ROI time course by dividing by starting intensity, averaging the background fields to produce a dye bleaching time course ( $2 \mathrm{~h}$ bleaching $12.1 \pm 1.0 \%)$, and dividing each bouton ROI by bleaching at corresponding time points.

Compounds and drug treatments. Forskolin (Biomol) was bath applied at a final concentration of $10 \mathrm{nM}$ or $50 \mu \mathrm{m}$ in ACSF, the selective type-IV phosphodiesterase inhibitor rolipram (Sigma-Aldrich) at $1 \mu \mathrm{M}$, and bicuculline (Tocris Bioscience) at $10 \mu \mathrm{M}$. The cell-permeable PKA inhibitor $\mathrm{H} 89$ was bath applied at $10 \mu \mathrm{M}$ concentration at least $30 \mathrm{~min}$ before bath application of $10 \mu \mathrm{M}$ NMDA. The synthetic peptide PKA inhibitor PKI (100 $\mu \mathrm{M}$ in patch pipette) was intracellularly infused into individual CA1 pyramidal neurons of slices from 15-d-old wild-type mice at least $20 \mathrm{~min}$ before bath application of $10 \mu \mathrm{M}$ NMDA. For induction of longlasting potentiation (LLP), slices were perfused for 15 min with ACSF containing $10 \mathrm{nM}$ or $50 \mu \mathrm{M}$ forskolin, $1 \mu \mathrm{M}$ rolipram, and $10 \mu \mathrm{M}$ bicuculline, while fEPSPs were recorded at a test frequency of $0.033 \mathrm{~Hz}$. Recordings were continued for an additional $60 \mathrm{~min}$ to wash out forskolin, rolipram, and bicuculline.

Western blot analysis of CREB phosphorylation. SDS PAGE and Western blot analysis of isolated hippocampal CA1 slice homogenates from 15 -d-old male and female wild-type and synpo ${ }^{-1-}$ mice was done as previously described (Mundel et al., 1997; Asanuma et al., 2005). Primary antibodies against total CAMP response element-binding protein (CREB; Abcam), phospho-CREB (Abcam) and GAPDH (Calbiochem) were used at 1:1000. Horseradish peroxidase-conjugated secondary antibodies (Promega) were used at 1:20,000.

Immunofluorescence microscopy of phosphorylated CREB. Immunfluorescence microcopy of phospho-CREB was done as reported previously (Lu et al., 1999). Fluorescence images were captured using a two-photon laser-scanning Olympus BX61WI microscope with a $60 \times / 0.9 \mathrm{nA}$ objective lens. A Mai/Tai laser (Solid State Laser) was tuned to $820 \mathrm{~nm}$ excitation wavelength, and green (HQ525/50) fluorescence intensity was measured with a photonmultiplier tube. In the transfluorescent pathway, a $565 \mathrm{~nm}$ dichroic mirror was used to separate green and red fluorescence to eliminate transmitted or reflected light (Chroma Technology). Image acquisition was controlled by Olympus software Fluoview FV300.

Statistical analyses. All data were analyzed by ANOVA and independent Student's $t$ test using SPSS software. The significance level was preset to $p<0.05$. Data are presented as mean \pm SEM across experiments.

\section{Results}

\section{Dendritic spine expansion requires synaptopodin}

Under baseline conditions, the number and size of spines on apical dendrites of Golgi-impregnated layer 5 pyramidal neurons and on dendrites of CA1 pyramidal neurons are similar in wildtype and synaptopodin-deficient mice (Deller et al., 2003). To test whether PKA induces spine volumetric expansion in a synaptopodin-dependent fashion, we used two-photon laser scanning microscopy to dynamically image shape changes of individual dendritic spines from tertiary branches of neurons filled with the fluorescent dye AlexaFluor 594 following bath application of the adenylate cyclase activator forskolin $(50 \mu \mathrm{M})$ plus the selective type IV phosphodiesterase inhibitor rolipram $(10 \mu \mathrm{M}$; Fig. 1A). These experiments revealed a significant, long-lasting, expansion of dendritic spine volumes in hippocampal slices from 15 -d-old wild-type, but not synpo ${ }^{-1-}$, mice (Fig. $1 B, C$ ). This long-term increase in spine volume was associated with a longterm amplitude enhancement of Schaffer collateral-evoked 
A

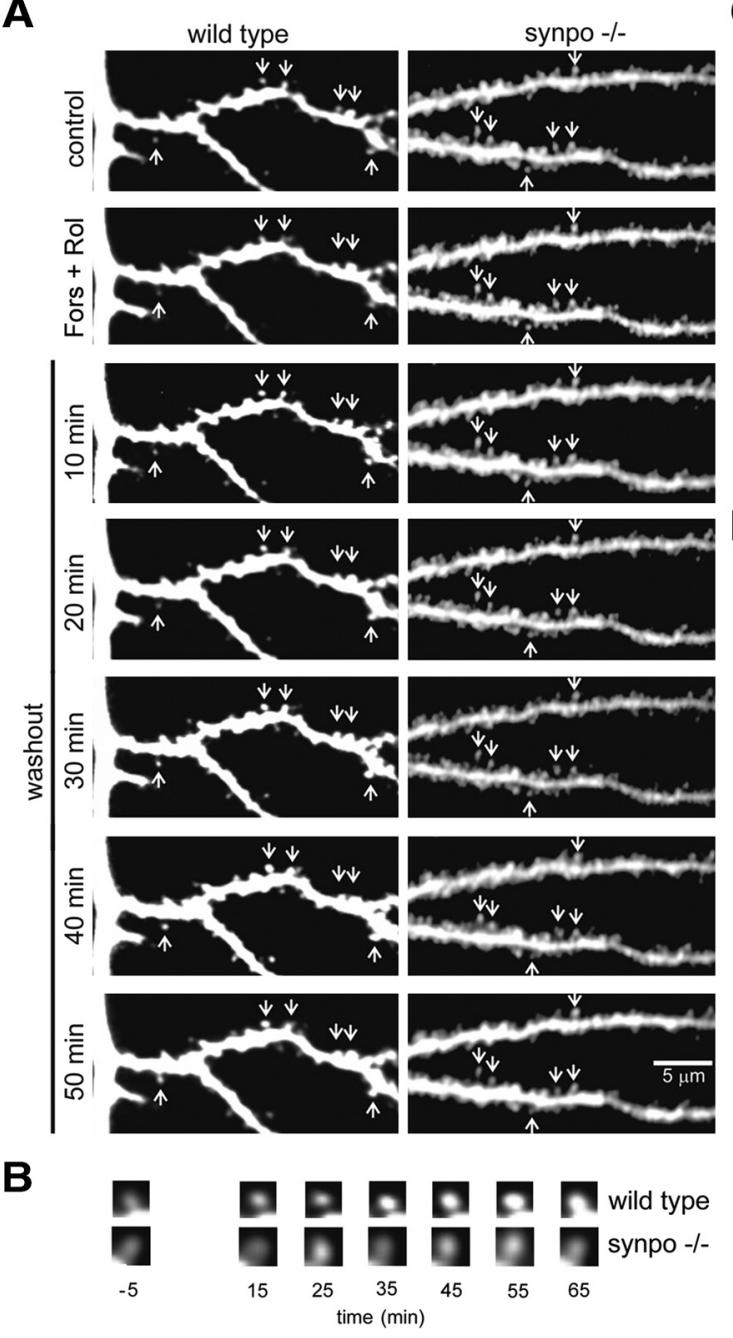

C

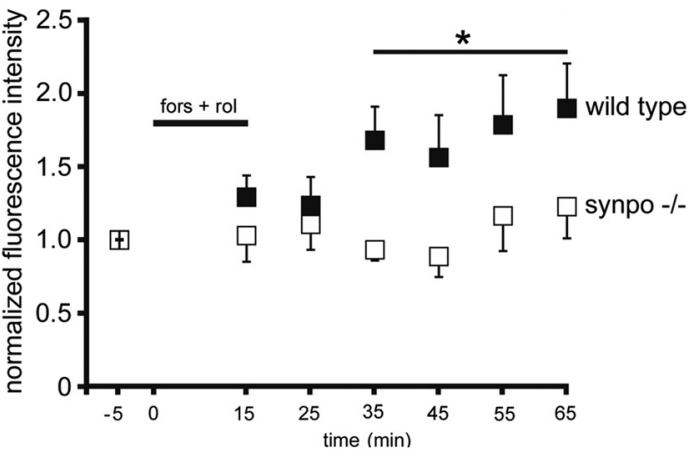

D

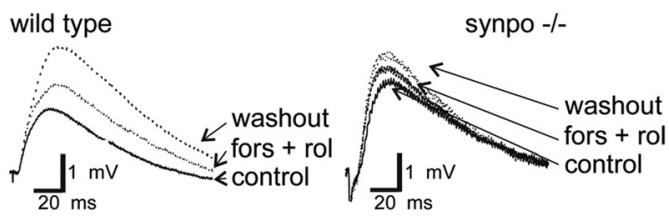

E

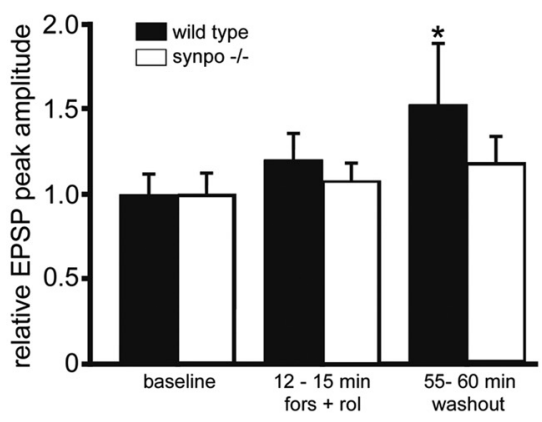

Figure 1. CAMP-induced dendritic spine expansion and LTP are impaired in synpo ${ }^{-1-}$ mice. $A$, Representative two-photon images showing the effect of bath application of $50 \mu$ m forskolin plus $10 \mu \mathrm{m}$ rolipram (Fors + Rol) on dendritic spines (arrows) from AlexaFluor 594 filled apical dendrites of 15 -d-old wild-type and synpo ${ }^{-1-}$ CA1 pyramidal neurons. Scale bar, $5 \mu$ m. $\boldsymbol{B}$, Time course of Fors + Rol-induced changes in dendritic spine fluorescence intensity in wild-type and synpo ${ }^{-1-}$ neurons. $C$, Quantitative time course analysis of cAMP-induced spine expansion. Each point represents mean \pm SEM spine fluorescence normalized to preforskolin intensity (Fors + Rol were added at time $0 ;{ }^{*} p<0.05$ ) in wild-type $\left(n=65\right.$ spines in eight slices) versus synpo ${ }^{-1-}$ ( $n=$ 72 spines in eight slices) spines. $\boldsymbol{D}$, Representative Schaffer collateral-evoked EPSPs in (A1 pyramidal neurons in slices from wild-type and synpo ${ }^{-1-}$ mice before (control), during a 15 min bath application (Fors + Rol), and after a 60 min washout (washout) of $50 \mu \mathrm{m}$ forskolin plus $10 \mu \mathrm{m}$ rolipram. $\boldsymbol{E}$, Mean \pm SEM of Schaffer collateral-evoked normalized peak EPSP amplitudes of CA1 pyramidal neurons in slices from wild-type $(n=8)$ versus synpo ${ }^{-1-}(n=10)$ mice before (baseline), during (Fors + Rol), and after $55-60$ min washout (washout) of $50 \mu \mathrm{m}$ forskolin plus $10 \mu \mathrm{m}$ rolipram $\left({ }^{*} p<0.05\right)$.

EPSPs in single CA1 pyramidal neurons in slices from wild-type, but not synpo ${ }^{-1-}$, mice (Fig. $1 D, E$ ), These results indicate that synaptopodin is necessary for full expression of cAMP-mediated enhancement of dendritic spine volume and synaptic transmission.

NMDA-induced, PKA-dependent dendritic spine expansion is impaired in synpo ${ }^{-/-}$mice

The observed absence of cAMP-induced spine expansion in synpo $^{-1-}$ mice prompted us to explore whether synaptopodin is an essential downstream mediator of NMDA-induced, PKA-dependent stable spine expansion (Yang et al., 2008). To test this hypothesis, we visualized NMDA-induced changes in CA1 pyramidal neuron dendritic spine volume in slices from 15 -d-old wild-type and synpo ${ }^{-1-}$ mice. NMDA $(10 \mu \mathrm{M})$ induced a rapid, long-lasting (at least $1 \mathrm{~h}$ post-NMDA) increase in dendritic spine size in wild-type, but not synpo ${ }^{-1-}$, mice (Fig. 2A). Quantitative analysis showed an $\sim 50 \%$ increase in spine fluorescent size in CA1 pyramidal neurons of wild-type, but not synpo ${ }^{-1-}$, mice (Fig. $2 B, C$ ). Bath application of the PKA inhibitor H-89 (10 $\mu \mathrm{M})$ blocked NMDA-induced increases in size of apical dendritic spines in CA1 pyramidal neurons of slices from 15-d-old wild-type mice (Fig. $3 A, B$ ), indicating that NMDA-R signaling regulates dendritic spine shape via PKA and synaptopodin-dependent pathways during postnatal mouse brain development. As H89 can inhibit kinases other than PKA as well as some channels (Bain et al., 2007), we confirmed these findings with a second PKA inhibitor. We repeated the NMDA-induced spine expansion studies following intracellular infusion of PKI, a potent, competitive, synthetic peptide inhibitor of PKA (Cheng et al., 1986). Intracellular infusion of PKI $(100 \mu \mathrm{M})$ into individual CA1 pyramidal neurons of slices from 15-d-old wild-type mice completely blocked the NMDA-induced increases in size of apical dendritic spines in CA1 pyramidal neurons, confirming the involvement of PKA in NMDA-induced spine expansion at this developmental age (Fig. 3C,D). 
A
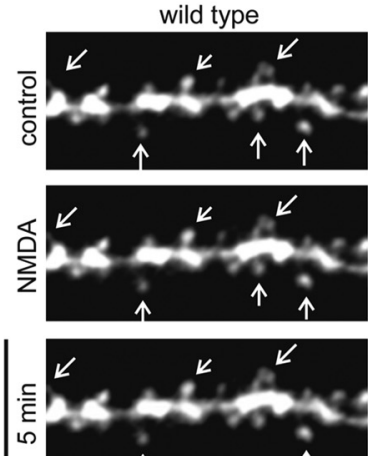

个
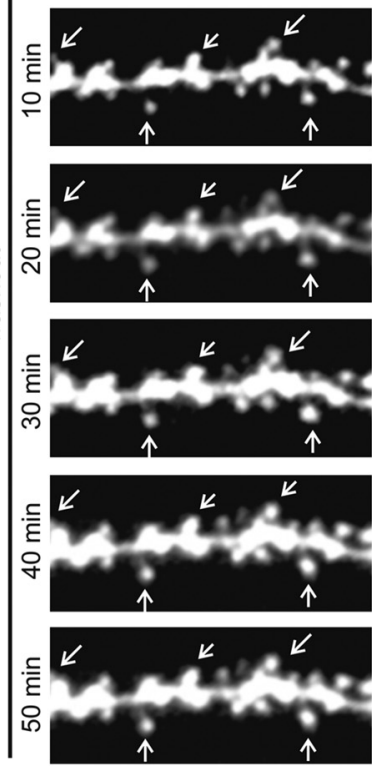

synpo -/-
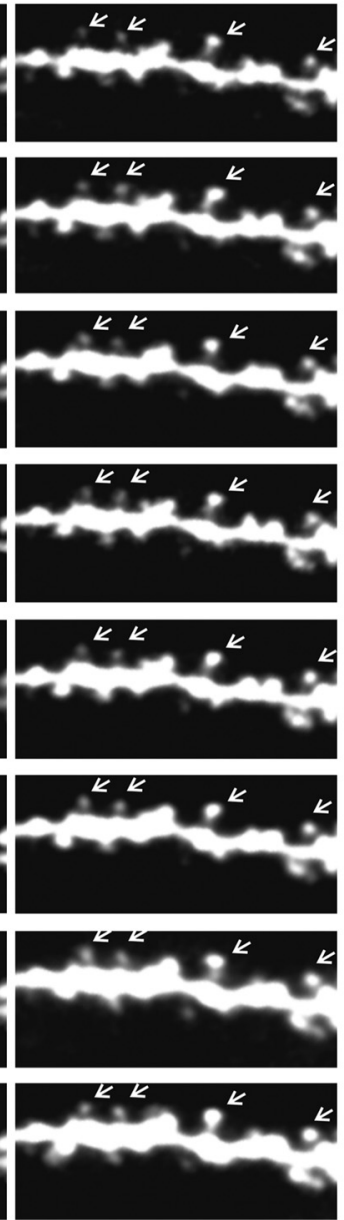

B

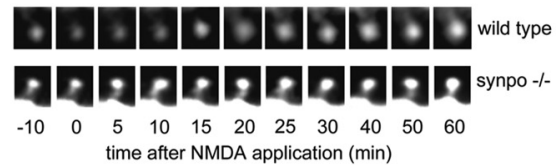

C

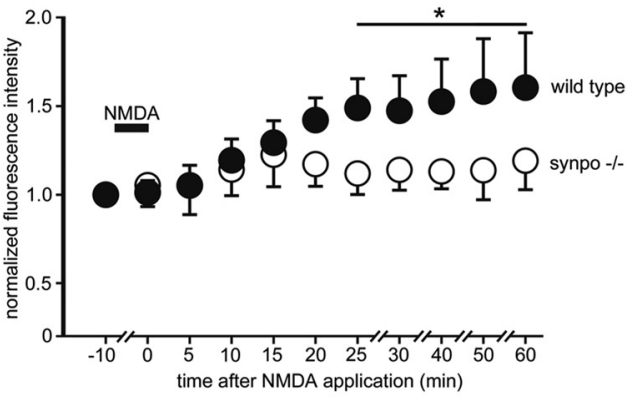

Figure 2. Synaptopodin is required for NMDA-induced dendritic spine expansion. $A$, Time-lapse two-photon microscopy illustrating the effect of a 5 min bath application of $10 \mu \mathrm{m}$ NMDA on dendritic spines (arrows) of AlexaFluor 594-filled apical dendrites from representative wild-type and synpo ${ }^{-1-}$ CA1 pyramidal neurons before (control), during (NMDA), and after (washout) 5 min exposure to $10 \mu \mathrm{M}$ NMDA. $\boldsymbol{B}$, Time course of NMDA-induced changes in dendritic spine fluorescence intensity in wild-type and synpo ${ }^{-1-}$ neurons. $\boldsymbol{C}$, Quantitative time course analysis of NMDA-induced changes in representative dendritic spine fluorescence intensity. Each point is mean $\pm S E M$ spine fluorescence normalized to predrug intensity $\left({ }^{*} p<0.05, t\right.$ test, compared with pre-NMDA normalized baseline intensity in wild-type ( $n=62$ spines in eight slices) versus synpo ${ }^{-1-}(n=70$ spines in nine slices) spines).

Postnatal LTP is reduced in synpo ${ }^{-1-}$ mice

Induction of LTP in immature rats ( $<9 \mathrm{~d}$ of age) requires activation of PKA (Yasuda et al., 2003). Because synaptopodin is a substrate of PKA (Faul et al., 2008) required for PKA-dependent spine expansion (Fig. $1 A-C$ ), we hypothesized that LTP is impaired in immature synpo ${ }^{-1-}$ mice. Consistent with this hypothesis, the magnitude of LTP at Schaffer collateral-CA1 synapses was significantly reduced in slices from both 15 (Fig. 4A) and 21 -d-old (Fig. $4 B$ ) synpo $^{-1-}$ mice (25 and $20 \%$, respectively; $p<$ 0.05 , Student's $t$ test). In contrast, slices from 2 - and 6-month-old synpo $^{-1-}$ mice showed no reduction in the magnitude of Schaffer collateral-CA1 LTP (Fig. 4C,D).

Maximal LTP, presynaptic transmitter release, and LTD are all normal in synpo ${ }^{-/-}$mice

The observed impairment of LTP in developing synpo ${ }^{-1-}$ mice could result from an increased threshold for LTP induction, and/or decreased capacity for LTP expression. To differentiate between these possibilities, we examined the amplitude of maximal LTP induced by repeated high-frequency stimulus trains $(100 \mathrm{~Hz} / 4$ pulse $\times 10$ bursts $200 \mathrm{~ms}$ interburst interval, five trains in all) applied once each 10 min until LTP reached a maximal amplitude. The ceiling for maximal LTP at Schaffer collateral-CA1 synapses was normal in 15-d-old synpo ${ }^{-1-}$ mice (Fig. 5A), indicating that synaptopodin deficiency does not impair the capacity to express LTP. To test whether LTP reduction in developing synpo ${ }^{-1-}$ mice resulted from presynaptic impairments in glutamate release, we measured directly the rate of vesicular release of the styryl dye FM1-43 loaded by hypertonic shock into the rapidly recycling vesicle pool of Schaffer collateral presynaptic terminals in stratum radiatum of the CA1 region in slices from wild-type and synpo ${ }^{-1-}$ mice (Fig. 5B). We found that the rates of stimulus-evoked presynaptic transmitter release were normal in synpo ${ }^{-1-}$ mice (Fig. $5 C$ ). We also tested whether the observed impairment of developmental LTP in synpo ${ }^{-/-}$mice might have resulted from a masking increase in the magnitude of long-term depression of synaptic transmission (LTD). We analyzed LTD at Schaffer collateral-CA1 synapses induced by a low-frequency train of Schaffer collateral stimulation $(2 \mathrm{~Hz} / 10 \mathrm{~min})$. The magnitude of LTD was normal in slices from either 15- (Fig. 5D) or 21-d-old (Fig. 5E) synpo ${ }^{-1-}$ mice, confirming that synaptopodin plays a selective regulatory role in the induction of LTP, but not LTD. 
A

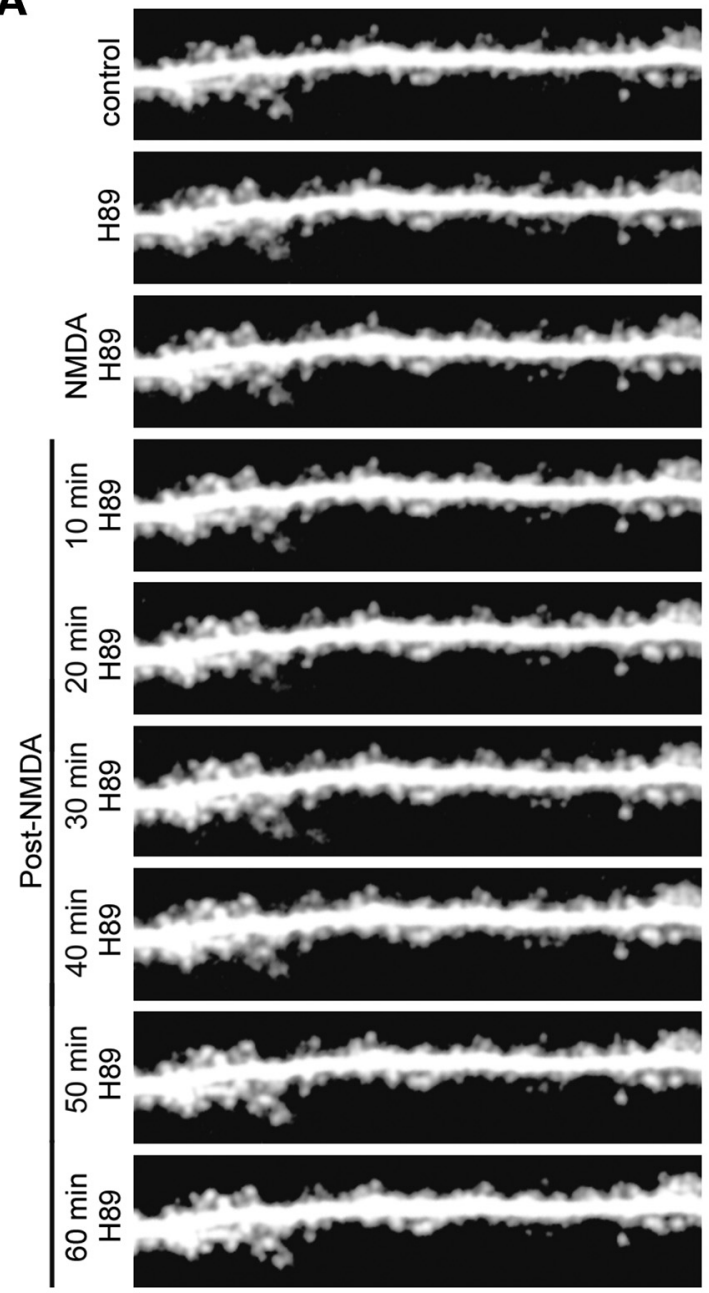

B

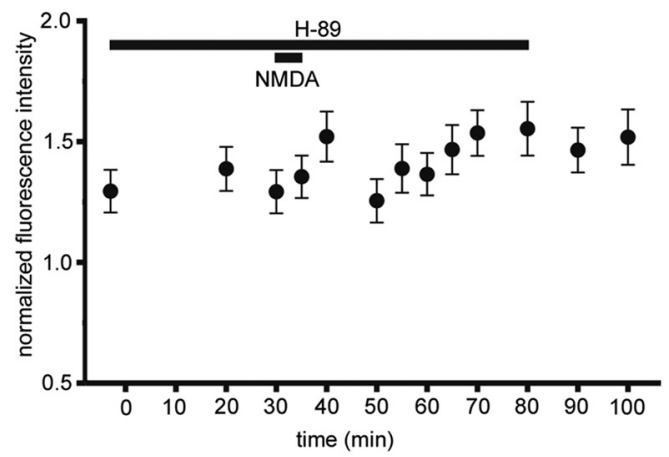

C
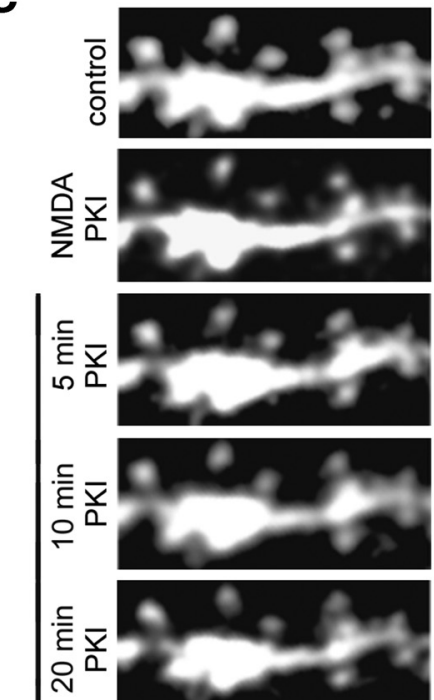

$\sum_{\substack{1 \\ \vdots}}^{\frac{1}{2}}$

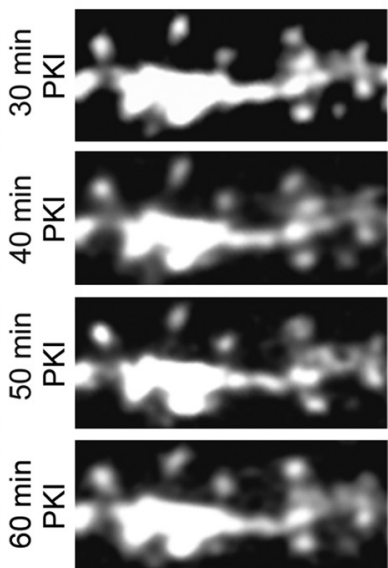

D

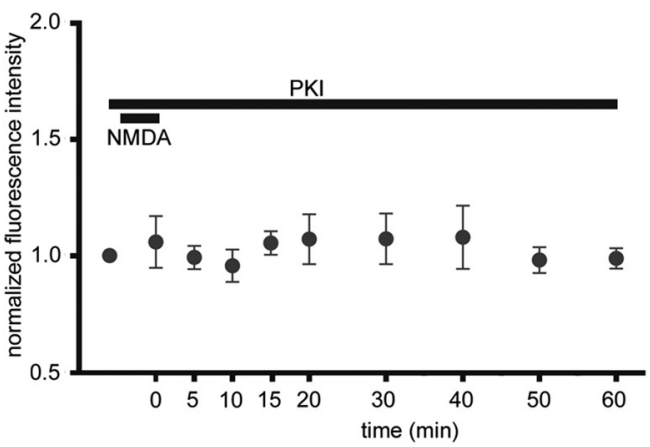

Figure 3. PKA inhibition blocks NMDA-induced dendritic spine expansion. $A$, Time-lapse two-photon laser scanning microscopy images demonstrating the inhibitory effect of the PKA inhibitor H89 (10 $\mu \mathrm{M}$ ) on NMDA-induced dendritic spine expansion from representative 15-d-old wild-type CA1 pyramidal neurons before (control), during (NMDA) and after (post-NMDA) a 5 min exposure to NMDA $(10 \mu \mathrm{M})$. B, Quantitative analysis of the time course of H89-mediated inhibition of NMDA-induced dendritic spine increase. C, Time-lapse two-photon laser scanning microscopy images demonstrating that postsynaptic infusion of the specific peptide PKA inhibitor PKI (100 $\mu \mathrm{m}$ in patch pipette) prevents NMDA-induced dendritic spine expansion in representative 15-d-old wild-type CA1 pyramidal neurons before (control), during (NMDA), and after (post-NMDA) a 5 min exposure to NMDA (10 $\mu \mathrm{M})$. $\boldsymbol{D}$, Quantitative analysis of the time course of blockade of NMDA-induced dendritic spine increase by postsynaptic PKI.

\section{Synaptopodin is required for cAMP-mediated} developmental LTP

LTP at immature Schaffer collateral-CA1 synapses in neonatal rat brain has been shown previously to exhibit a substantial, though not complete, dependence on PKA activity (Yasuda et al., 2003). We therefore tested whether this was also true in mice. We found that the PKA inhibitor H-89 $(10 \mu \mathrm{M})$ almost completely blocked the spine expansion induced by bath application of forskolin $(50 \mu \mathrm{M})$ plus rolipram $(10 \mu \mathrm{M}$; Fig. $6 A, B)$. This inhibition of spine expansion correlated with a substantial, but not complete, inhibition of LTP induction at Schaffer collateral-CA1 synapses in hippocampal slices from either 15-d-old (Fig. 6C, red circles) or 21-d-old (Fig. 6C, black circles) wild-type mice. 
A

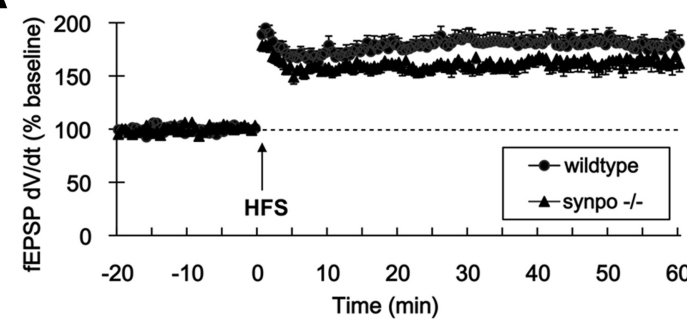

C

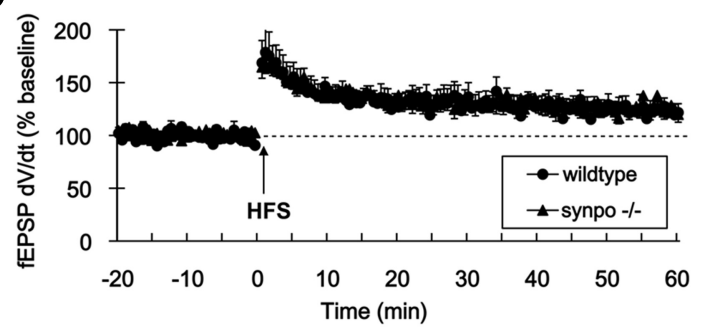

B

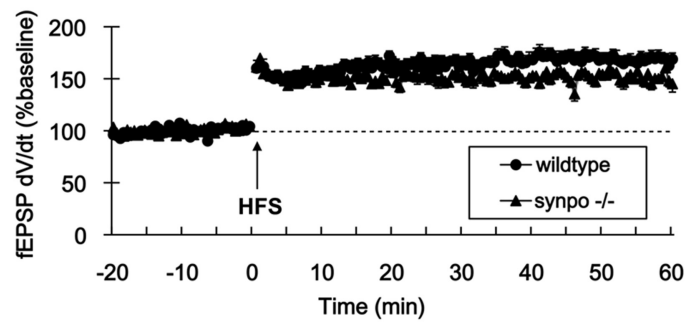

D

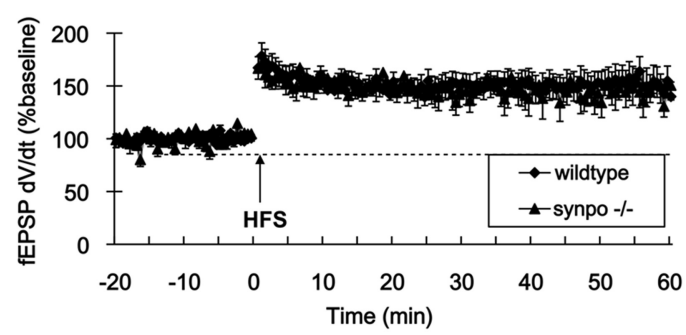

Figure 4. LTP but not LTD in neonatal hippocampus requires synaptopodin. Time course of LTP induced by Schaffer collateral high-frequency theta burst stimulation (HFS; $100 \mathrm{~Hz} / 4$ pulse $\times 10$ bursts; arrow) in field CA1. A, 15-d-old synpo ${ }^{-1-}$ (filled triangles, $n=15$ ) versus wild-type control mice (filled circles, $n=17$ ). $B$, Twenty-one-day-old synpo ${ }^{-1-}$ mice (filled triangles, $n=12$ ) versus wild-type littermates (filled circles, $n=15$ ). C, Two-month-old synpo ${ }^{-1-}$ (filled triangles, $n=9$ ) versus wild-type mice (filled circles, $n=6$ ). $\boldsymbol{D}_{\text {, Six-month-old synpo }}{ }^{-1-}$ (filled triangles, $n=7$ ) versus wild-type mice (filled circles, $n=13$ ).

A

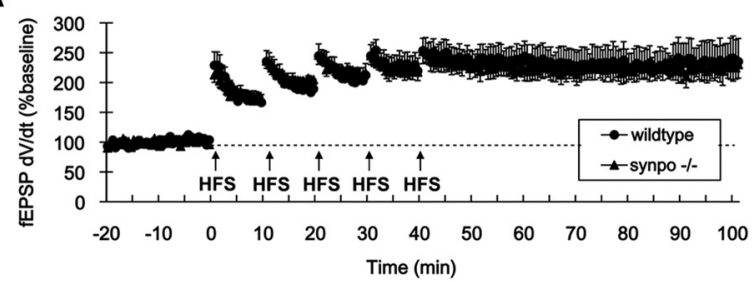

B

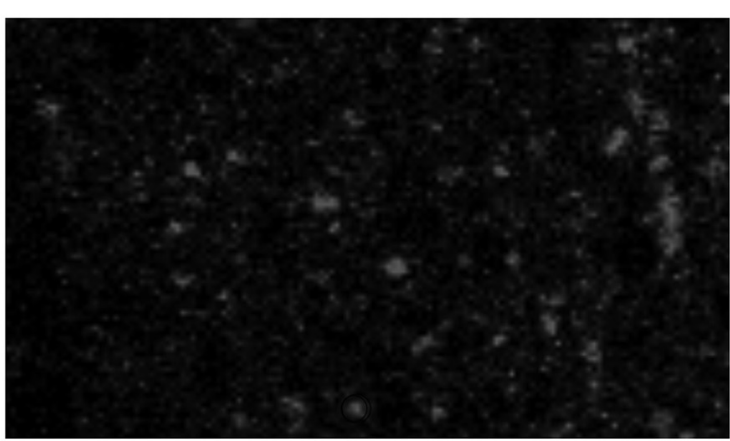

C

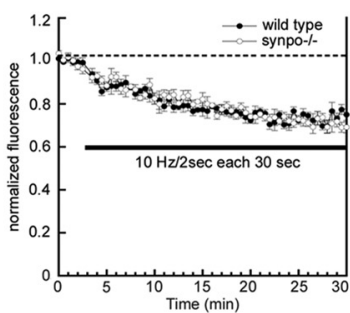

D

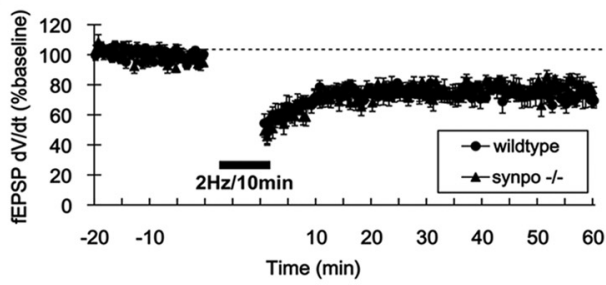

E

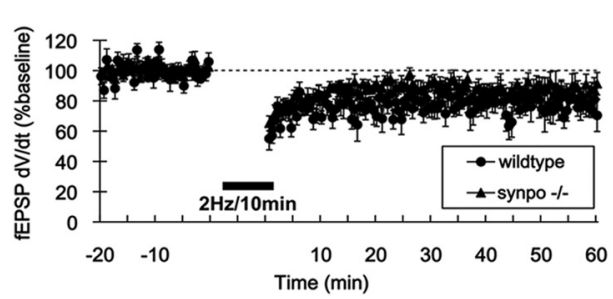

Figure 5. Maximal LTP, presynaptic transmitter release and LTD are normal in synpo ${ }^{-1-}$ mice. $A$, Time course of LTP induced by repeated trains of Schaffer collateral HFS ( $100 \mathrm{~Hz} / 4$ pulse $\times 10$ bursts; arrows) applied each $10 \mathrm{~min}$ in field CA1 of slices from 15 -d-old synpo ${ }^{-1-}$ (filled triangles, $n=12$ ) and wild-type control mice (filled circles, $n=10$ ). Each point is mean \pm SEM of $n$ slices. $B, C$, Vesicular release from presynaptic Schaffer collateral-CA1 terminals is normal in synpo ${ }^{-1-}$ mice. $\boldsymbol{B}$, Representative pseudocolor two-photon excitation fluorescent image of RRP puncta in stratum radiatum of field CA1 in a control slice. C, Time courses of Schaffer collateral stimulus-evoked (solid bar; $10 \mathrm{~Hz} / 2 \mathrm{~s}$ bursts each $30 \mathrm{~s}$ ) FM1-43 destaining from the RRP vesicle pool in hippocampal slices from synpo ${ }^{-1-}$ mice (open circles; $n=4$ slices) versus wild-type controls (filled circles; $\left.n=4\right)$ ). D, $E$, Time course of LFS train $(2 \mathrm{~Hz} / 10 \mathrm{~min}$; solid bar) induced LTD in field CA1. $\boldsymbol{E}, 15$-d-old synpo ${ }^{-1-}$ (filled triangles, $n=10$ ) versus wild-type mice (filled circles, $n=9$ ). $\boldsymbol{F}$, Twenty-one-day-old synpo ${ }^{-1-}$ (filled triangles, $n=9$ ) versus wild-type mice (filled circles, $n=8$ ). Each point is mean \pm SEM of $n$ slices. 
A
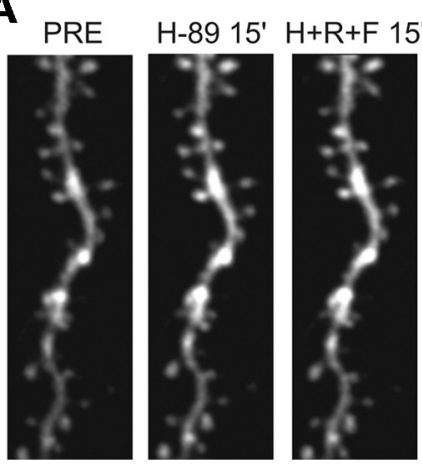

B

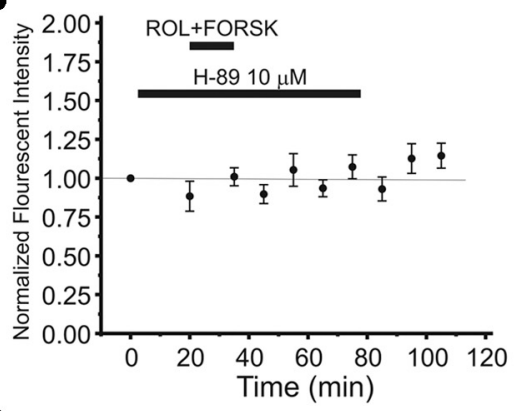

D

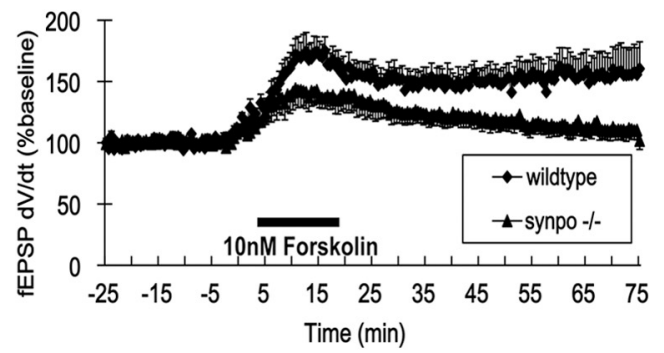

$\mathbf{F}$

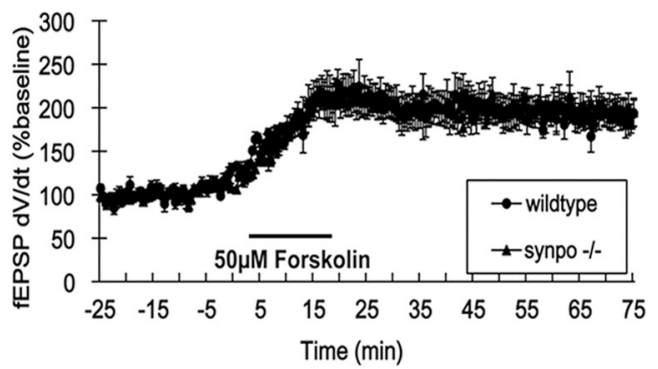

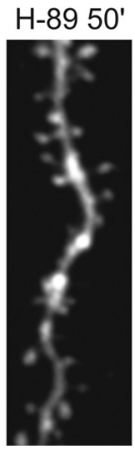

$\mathrm{H}-8960^{\prime}$

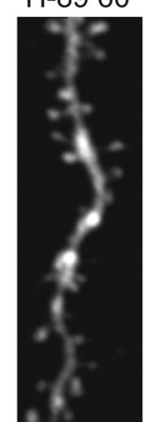

$\mathrm{H}-8970$
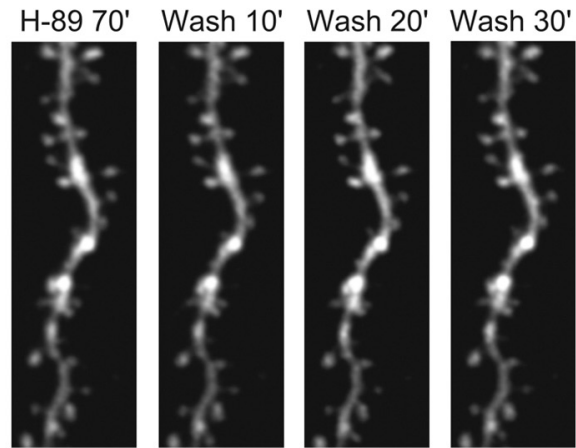

C

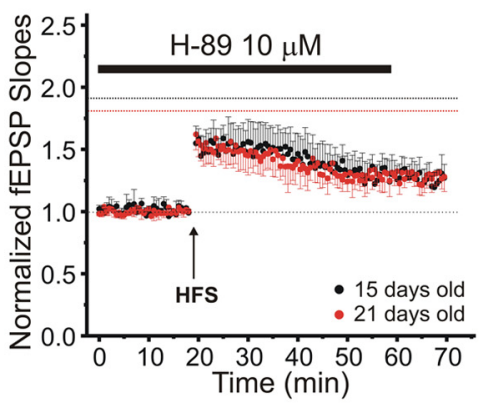

E

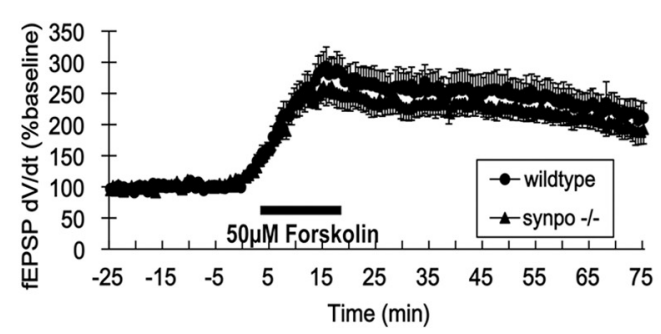

G

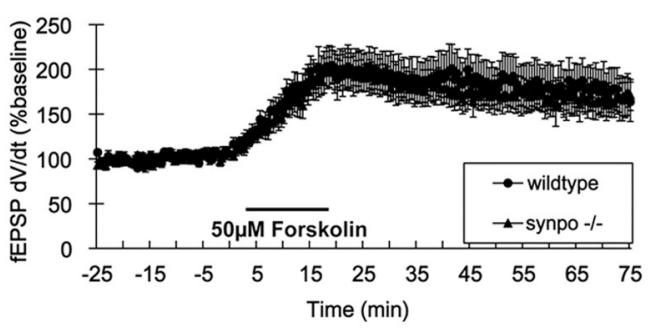

Figure 6. PKA-induced LTP in immature brain requires synaptopodin. $A, B$, PKA inhibition blocks cAMP-induced spine expansion. $A$, Time-lapse two-photon laser scanning microscopy images demonstrating the inhibitory effect of the PKA inhibitor H89 $(10 \mu \mathrm{M})$ on dendritic spine expansion produced by forskolin (FORSK, $50 \mu \mathrm{M})$ plus rolipram (ROL, $10 \mu \mathrm{M})$ in a representative 15-d-old wild-type CA1 pyramidal neuron before (PRE), during ( $F+R+K)$, and after ( $\mathrm{H}-89)$ exposure to FORSK plus ROL in the presence of H89 to block PKA. B, Quantitative time course of H89-mediated inhibition of cAMP-induced dendritic spine expansion ( $n=51$ apical dendritic spines from two pyramidal neurons). C, PKA inhibition markedly reduces LTP in immature slices. Time course of LTP induced by Schaffer collateral HFS (100 Hz/4 pulse $\times 10$ bursts/ arrow) in the presence of bath-applied H89 (10 $\mu \mathrm{m}$; black bar) in field CA1 of hippocampal slices from 15-d-old (black circles; $n=$ 7) or 21-d-old (red circles; $n=8$ ) wild-type control mice. $\boldsymbol{D}$, Time course of LLP of Schaffer collateral-evoked field potentials in field CA1 induced by $10 \mathrm{~nm}$ forskolin (solid bar) in slices from 15 -d-old synpo $^{-l-}$ (filled triangles, $n=16$ ) versus wild-type mice (filled circles, $n=8$ ). E, Time course of forskolin ( $50 \mu \mathrm{m}$; solid bar) induced LLP of Schaffer collateral-CA1 transmission slices from $15-\mathrm{d}$-old synpo $^{-l-}$ (filled triangles, $n=11$ ) versus wild-type mice (filled circles, $n=11$ ). Each point is mean \pm SEM of $n$ slices. F, G, Forskolin induced LLP at Schaffer collateral-CA1 synapses is not altered in slices from adult synpo ${ }^{-1-}$ mice. Time course of LLP of Schaffer collateral-evoked field potentials in field CA1 induced by bath application of forskolin (50 $\mu \mathrm{m}$; solid bar) in slices from (F) 2-month-old synpo ${ }^{-1-}$ (filled triangles, $n=9$ ) and wild-type control mice (filled circles, $n=6$ ) and $(\boldsymbol{G}) 6$-month-old synpo ${ }^{-1-}$ (filled triangles, $n=8$ ) and wild-type control mice (filled circles, $n=6)$. Each point is mean \pm SEM of $n$ slices.

Because synaptopodin is a substrate of PKA (Faul et al., 2008), we tested directly whether synaptopodin was necessary for cAMP-mediated LTP in young mice. We measured the amplitude of cAMP-induced LLP at Schaffer collateral-CA1 synapses elicited by bath application of forskolin plus rolipram to elevate [cAMP]. A 15 min bath application of a submaximal concentra- tion of forskolin ( $10 \mathrm{nM})$ plus rolipram $(1 \mu \mathrm{M})$ elicited substantial LLP in slices from 15-d-old wild-type mice, and this LLP was significantly impaired in synpo ${ }^{-1-}$ mice (Fig. $6 D ; p<0.05$, Student's $t$ test). A supramaximal concentration of forskolin $(50 \mu \mathrm{M})$ produced a larger LLP, which was significantly reduced in 15-dold synpo $^{-1-}$ mice (Fig. $6 E ; p<0.05$, Student's $t$ test). In con- 
A
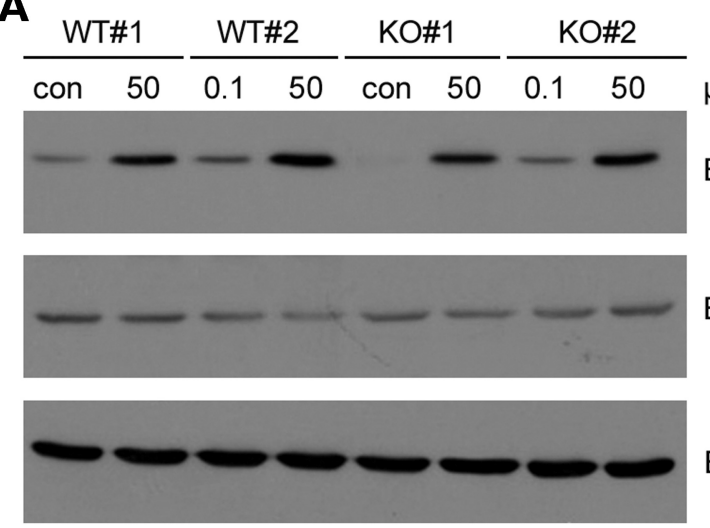

C

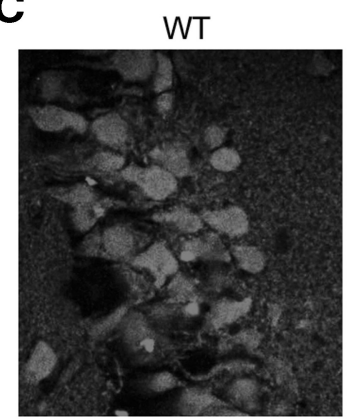

anti-phospho-CREB
B

$\mu M$ Forskolin

Blot: p-CREB

Blot: CREB

Blot: GAPDH

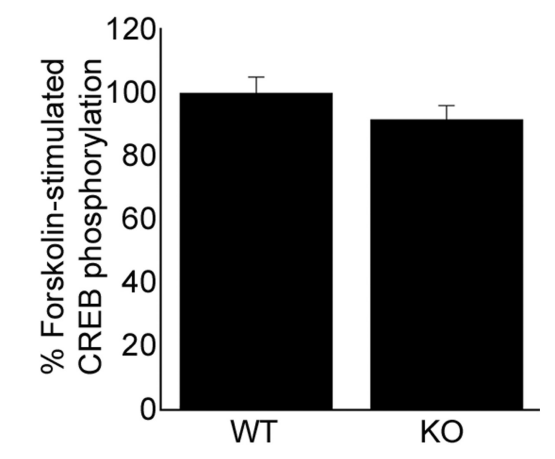

D

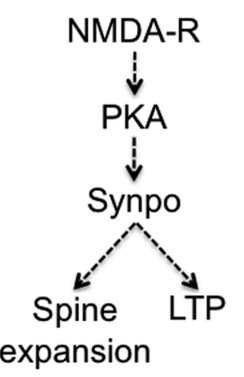

Figure 7. PKA-mediated CREB phosphorylation is normal in brains of synpo ${ }^{-/-}$mice. $A, B$, Forskolin-stimulated phospho-CREB protein levels $\left(n=4\right.$ wild-type, 4 synpo ${ }^{-1-}$ mice, not significant) and phospho-CREB immunofluorescence $(\boldsymbol{C})$ are not impaired in brains of synpo ${ }^{-1-}(K 0)$ mice compared with wild-type (WT) mice. $\boldsymbol{D}$, A model for the role of synaptopodin as a downstream mediator of NMDA-induced, PKA-dependent developmental dendritic spine extension and LTP.

trast, cAMP-dependent LLP was not altered in slices from 2- or 6-month-old synpo ${ }^{-1-}$ mice (Fig. $6 F, G$ ), ages when stimulusevoked LTP (Fig. 4C,D) was also not affected by the absence of synaptopodin.

\section{cAMP-induced CREB phosphorylation is normal in synpo $^{-1-}$ mice}

To test whether the observed reduction of forskolin-stimulated LLP resulted from decreased activation of PKA-CREB signaling (Nguyen and Woo, 2003) we analyzed CREB phosphorylation in brains from P15 wild-type and synpo ${ }^{-1-}$ mice. We detected no differences in forskolin-stimulated CREB phosphorylation between wild-type and synpo ${ }^{-1-}$ mice by either Western blotting of isolated CA1 slices (Fig. $7 A, B$ ), or immunocytochemistry of the CA1 pyramidal cell body layer (Fig. 7C). These data show that PKA-CREB signaling is normal in synpo ${ }^{-1-}$ mice when cAMPdependent postnatal spine size expansion and LTP are impaired.

\section{Discussion}

The results of this study revealed that the actin cytoskeletal regulator synaptopodin is required for NMDA-mediated, PKAdependent stable spine expansion and LTP of synaptic transmission (Fig. 7D). Consistent with the functional role of synaptopodin as a regulator of actin dynamics, both NMDA and cAMP-induced long-term increases in dendritic spine volume were absent in CA1 pyramidal neurons of mice lacking synaptopodin. In keeping with previous studies in rats (Yasuda et al., 2003), our data identify cAMP as a critical regulator of dendritic spine morphology and long-term plasticity of synaptic transmission in the developing mouse hippocampus. Moreover, they show that synaptopodin is an important downstream mediator of these cAMP-dependent effects. Although cAMP-dependent LTP elicited by coapplication of forskolin/rolipram is a compound phenomenon for which there is evidence of both presynaptic and postsynaptic alterations (Bolshakov et al., 1997; Yang et al., 2008), our data suggest that synaptopodin is an important regulator of cAMP-dependent, cyctoskeleton-mediated enhancement of postsynaptic dendritic spine volume.

The Rho family of small GTPases Racl and Cdc42 promote the development and maintenance of dendritic spines, whereas RhoA inhibits spine formation (Tashiro and Yuste, 2008). Important changes in synaptic structure and function associated with long-term memory are thought to focus on the point of excitatory synaptic contact, the dendritic spine, and to involve both biochemical alterations and persistent changes in spine shape (Fischer et al., 1998; Matus et al., 2000; Ethell and Pasquale, 2005; Kasai et al., 2010). LTP elicits both transient (Lang et al., 2004) and persistent (Yang et al., 2008) NMDA-R-dependent expansion in dendritic spine volume, which in turn require dynamic regulation of the spine actin cytoskeleton (Fukazawa et al., 2003; Honkura et al., 2008; Kasai et al., 2010). The persistence of NMDA-R-dependent spine expansion requires local protein synthesis (Yang et al., 2008), PKA (Yang et al., 2008), and CaMKII (Fortin et al., 2010) activation, and postsynaptic exocytosis-dependent AMPA-R delivery to the spine surface (Park et al., 2004). Our current observations now point to an essential role for synaptopodin in NMDA-R-induced and cAMP-dependent spine remodeling, independent of phosphorylation of the transcription factor CREB.

Future studies are needed to determine whether synaptopodin enhances dendritic spine expansion and LTP via its effects on Rho GTPases, similar to the regulation of the actin cytoskeleton and 
cell motility in podocytes, fibroblasts, and cancer cells (Asanuma et al., 2006; Yanagida-Asanuma et al., 2007; Wong et al., 2012). Together, the results of the present study extend our understanding of the role of synaptopodin in the brain. The effects of cAMP/ PKA signaling on dendritic spine dynamics and LTP in hippocampal neurons during postnatal brain development are mediated by the actin organizing protein synaptopodin. Thus, synaptopodin emerges as a substrate of hippocampal PKA and key regulator of actin dynamics that enables alterations in dendritic spine morphology that underlie long-term synaptic plasticity critical for learning acquisition and memory storage (Honkura et al., 2008; Kasai et al., 2010).

\section{References}

Asanuma K, Kim K, Oh J, Giardino L, Chabanis S, Faul C, Reiser J, Mundel P (2005) Synaptopodin regulates the actin-bundling activity of alphaactinin in an isoform-specific manner. J Clin Invest 115:1188-1198. CrossRef Medline

Asanuma K, Yanagida-Asanuma E, Faul C, Tomino Y, Kim K, Mundel P (2006) Synaptopodin orchestrates actin organization and cell motility via regulation of RhoA signaling. Nat Cell Biol 8:485-491. CrossRef Medline

Bain J, Plater L, Elliott M, Shpiro N, Hastie CJ, McLauchlan H, Klevernic I, Arthur JS, Alessi DR, Cohen P (2007) The selectivity of protein kinase inhibitors: a further update. Biochem J 408:297-315. CrossRef Medline

Bolshakov VY, Golan H, Kandel ER, Siegelbaum SA (1997) Recruitment of new sites of synaptic transmission during the cAMP-dependent late phase of LTP at CA3-CA1 synapses in the hippocampus. Neuron 19:635-651. CrossRef Medline

Cheng HC, Kemp BE, Pearson RB, Smith AJ, Misconi L, Van Patten SM, Walsh DA (1986) A potent synthetic peptide inhibitor of the cAMPdependent protein kinase. J Biol Chem 261:989-992. Medline

Dell'Acqua ML, Smith KE, Gorski JA, Horne EA, Gibson ES, Gomez LL (2006) Regulation of neuronal PKA signaling through AKAP targeting dynamics. Eur J Cell Biol 85:627-633. CrossRef Medline

Deller T, Korte M, Chabanis S, Drakew A, Schwegler H, Stefani GG, Zuniga A, Schwarz K, Bonhoeffer T, Zeller R, Frotscher M, Mundel P (2003) Synaptopodin-deficient mice lack a spine apparatus and show deficits in synaptic plasticity. Proc Natl Acad Sci U S A 100:10494-10499. CrossRef Medline

Ethell IM, Pasquale EB (2005) Molecular mechanisms of dendritic spine development and remodeling. Prog Neurobiol 75:161-205. CrossRef Medline

Faul C, Donnelly M, Merscher-Gomez S, Chang YH, Franz S, Delfgaauw J, Chang JM, Choi HY, Campbell KN, Kim K, Reiser J, Mundel P (2008) The actin cytoskeleton of kidney podocytes is a direct target of the antiproteinuric effect of cyclosporine A. Nat Med 14:931-938. CrossRef Medline

Fischer M, Kaech S, Knutti D, Matus A (1998) Rapid actin-based plasticity in dendritic spines. Neuron 20:847-854. CrossRef Medline

Fortin DA, Davare MA, Srivastava T, Brady JD, Nygaard S, Derkach VA, Soderling TR (2010) Long-term potentiation-dependent spine enlargement requires synaptic $\mathrm{Ca}^{2+}$-permeable AMPA receptors recruited by CaM-kinase I. J Neurosci 30:11565-11575. CrossRef Medline

Fukazawa Y, Saitoh Y, Ozawa F, Ohta Y, Mizuno K, Inokuchi K (2003) Hippocampal LTP is accompanied by enhanced F-actin content within the dendritic spine that is essential for late LTP maintenance in vivo. Neuron 38:447-460. CrossRef Medline

Harris KM, Stevens JK (1989) Dendritic spines of CA1 pyramidal cells in the rat hippocampus: serial electron microscopy with reference to their biophysical characteristics. J Neurosci 9:2982-2997. Medline

Honkura N, Matsuzaki M, Noguchi J, Ellis-Davies GC, Kasai H (2008) The subspine organization of actin fibers regulates the structure and plasticity of dendritic spines. Neuron 57:719-729. CrossRef Medline

Kandel ER (2001) The molecular biology of memory storage: a dialogue between genes and synapses. Science 294:1030-1038. CrossRef Medline

Kasai H, Fukuda M, Watanabe S, Hayashi-Takagi A, Noguchi J (2010)
Structural dynamics of dendritic spines in memory and cognition. Trends Neurosci 33:121-129. CrossRef Medline

Lang C, Barco A, Zablow L, Kandel ER, Siegelbaum SA, Zakharenko SS (2004) Transient expansion of synaptically connected dendritic spines upon induction of hippocampal long-term potentiation. Proc Natl Acad Sci U S A 101:16665-16670. CrossRef Medline

Lisman J, Schulman H, Cline H (2002) The molecular basis of CaMKII function in synaptic and behavioural memory. Nat Rev Neurosci 3:175190. CrossRef Medline

Lu YF, Kandel ER, Hawkins RD (1999) Nitric oxide signaling contributes to late-phase LTP and CREB phosphorylation in the hippocampus. J Neurosci 19:10250-10261. Medline

Malenka RC, Nicoll RA (1999) Long-term potentiation: a decade of progress? Science 285:1870-1874. CrossRef Medline

Matsuzaki M, Honkura N, Ellis-Davies GC, Kasai H (2004) Structural basis of long-term potentiation in single dendritic spines. Nature 429:761-766. CrossRef Medline

Matus A, Brinkhaus H, Wagner U (2000) Actin dynamics in dendritic spines: a form of regulated plasticity at excitatory synapses. Hippocampus 10:555-560. CrossRef Medline

Mundel P, Heid HW, Mundel TM, Krüger M, Reiser J, Kriz W (1997) Synaptopodin: an actin-associated protein in telencephalic dendrites and renal podocytes. J Cell Biol 139:193-204. CrossRef Medline

Nguyen PV, Woo NH (2003) Regulation of hippocampal synaptic plasticity by cyclic AMP-dependent protein kinases. Prog Neurobiol 71:401-437. CrossRef Medline

Park M, Penick EC, Edwards JG, Kauer JA, Ehlers MD (2004) Recycling endosomes supply AMPA receptors for LTP. Science 305:1972-1975. CrossRef Medline

Schubert V, Dotti CG (2007) Transmitting on actin: synaptic control of dendritic architecture. J Cell Sci 120:205-212. CrossRef Medline

Stanton PK, Winterer J, Bailey CP, Kyrozis A, Raginov I, Laube G, Veh RW, Nguyen CQ, Müller W (2003) Long-term depression of presynaptic release from the readily releasable vesicle pool induced by NMDA receptordependent retrograde nitric oxide. J Neurosci 23:5936-5944. Medline

Stanton PK, Winterer J, Zhang XL, Müller W (2005) Imaging LTP of presynaptic release of FM1-43 from the rapidly recycling vesicle pool of Schaffer collateral-CA1 synapses in rat hippocampal slices. Eur J Neurosci 22:2451-2461. CrossRef Medline

Tashiro A, Yuste R (2008) Role of rho GTPases in the morphogenesis and motility of dendritic spines. Methods Enzymol 439:285-302. CrossRef Medline

Winterer J, Stanton PK, Müller W (2006) Direct monitoring of vesicular release and uptake in brain slices by multiphoton excitation of the styryl FM 1-43. Biotechniques 40:343-351. CrossRef Medline

Wong JS, Iorns E, Rheault MN, Ward TM, Rashmi P, Weber U, Lippman ME, Faul C, Mlodzik M, Mundel P (2012) Rescue of tropomyosin deficiency in Drosophila and human cancer cells by synaptopodin reveals a role of tropomyosin alpha in RhoA stabilization. EMBO J 31:1028-1040. CrossRef Medline

Yamazaki M, Matsuo R, Fukazawa Y, Ozawa F, Inokuchi K (2001) Regulated expression of an actin-associated protein, synaptopodin, during long-term potentiation. J Neurochem 79:192-199. CrossRef Medline

Yanagida-Asanuma E, Asanuma K, Kim K, Donnelly M, Young Choi H, Hyung Chang J, Suetsugu S, Tomino Y, Takenawa T, Faul C, Mundel P (2007) Synaptopodin protects against proteinuria by disrupting Cdc42: IRSp53:mena signaling complexes in kidney podocytes. Am J Pathol 171: 415-427. CrossRef Medline

Yang Y, Wang XB, Frerking M, Zhou Q (2008) Spine expansion and stabilization associated with long-term potentiation. J Neurosci 28:5740-5751. CrossRef Medline

Yasuda H, Barth AL, Stellwagen D, Malenka RC (2003) A developmental switch in the signaling cascades for LTP induction. Nat Neurosci 6:15-16. CrossRef Medline

Zhang XL, Sullivan JA, Moskal JR, Stanton PK (2008) A NMDA receptor glycine site partial agonist, GLYX-13, simultaneously enhances LTP and reduces LTD at Schaffer collateral-CA1 synapses in hippocampus. Neuropharmacology 55:1238-1250. CrossRef Medline 